\title{
Constitutional Reform and the Gender Diversification of Peak Courts
}

\author{
NANCY ARRINGTON California Polytechnic State University \\ LEEANN BASS Princeton University \\ ADAM GLYNN Emory University \\ JEFFREY K. STATON Emory University \\ BRIAN DELGADO Emory University \\ STAFFAN I. LINDBERG University of Gothenburg
}

\begin{abstract}
$D$ o the processes states use to select judges for peak courts influence gender diversity? Scholars have debated whether concentrating appointment power in a single individual or diffusing appointment power across many individuals best promotes gender diversification. Others have claimed that the precise structure of the process matters less than fundamental changes in the process. We clarify these theoretical mechanisms, derive testable implications concerning the appointment of the first woman to a state's highest court, and then develop a matched-pair research design within a Rosenbaum permutation approach to observational studies. Using a global sample beginning in 1970, we find that constitutional change to the judicial selection process decreases the time until the appointment of the first woman justice. These results reflect claims that point to institutional disruptions as critical drivers of gender diversity on important political posts.
\end{abstract}

$\mathbf{T}$ he world's peak courts, by which we refer to high ordinary or supreme courts as well as constitutional courts, are increasingly staffed by women (Hoekstra, Kittilson, and Bond 2014; Turquet et al. 2011). Within the last decade, gender parity or near parity has been reached on the national high courts of Angola, Australia, Canada, Ecuador, Rwanda, Serbia, and Slovenia. Women are increasingly serving as presidents of prestigious courts, such as the Supreme Courts of Canada and Israel as well as the Constitutional Chamber of the Costa Rican Supreme Court. This pattern is notable for several reasons. The presence of more women on peak courts may influence the law either because women understand the law in particular contexts or evaluate facts differently than men (e.g., Boyd, Epstein, and Martin 2010; Glynn and Sen 2015) or because male judges behave differently when they share the bench with women (Boyd, Epstein, and Martin 2010; Farhang and Wawro 2004). More diverse courts

\footnotetext{
Nancy Arrington (D), Assistant Professor, Department of Political Science, California Polytechnic State University-San Luis Obispo, naarring@calpoly.edu.

Leeann Bass (D), Lecturer, Department of Politics, Princeton University, lwbass@princeton.edu.

Adam Glynn, Associate Professor, Department of Political Science, Emory University, adam.glynn@emory.edu.

Jeffrey K. Staton (D), Professor, Department of Political Science, Emory University, jkstato@emory.edu.

Brian Delgado, Alumnus, Department of Political Science, Emory University, briandelgado1220@gmail.com.

Staffan I. Lindberg (D), Professor, Department of Political Science, University of Gothenburg, staffan.i.lindberg@pol.gu.se.
}

Received: July 03, 2019; revised: January 16, 2021; accepted: February 02, 2021. First published online: March 19, 2021. promote the legitimacy of the justice system (e.g., Kenney 2013; O'Connor and Azzarelli 2011), and increased gender diversity on important courts may be conceived of simply as an unalloyed normative good absent differences in the behavior of male and female justices (e.g., Malleson 2003). ${ }^{1}$

Despite these benefits, most states are far from parity (Turquet et al. 2011). Many have failed to begin to diversify until relatively recently. Whereas the first woman was appointed to the Mexican Supreme Court in 1961, the Constitutional Court and Supreme Court of Chile saw their first women judges in 1989 and 2001, respectively. While the first woman appointed to the Federal Constitutional Court in Germany was made in 1951, the first woman appointed to the Lord Appeal in Ordinary of the United Kingdom was made in $2004 .^{2}$ As Kang et al. (Forthcoming) note, the selection of the first woman justice to a peak court has an important symbolic value; it garners significant media coverage and can disrupt traditional perceptions of what and who peak court justices are. The selection of the first woman justice can also support further efforts to diversify. The presence of a female justice signals to other women that an appointment on the high court is possible. Dawuni (2016) notes that the appointment of women to peak courts opens up new channels of women-to-women mentoring, providing support for women at lower

\footnotetext{
${ }^{1}$ We focus on gender diversification. See Kang et al. (2020) and Kenney (2019) for intersectional approaches to diversification in the judiciary.

${ }^{2}$ We refer to María Cristina Salmorán de Tamayo (Mexico), Luz Bulnes Aldunate and María Antonia Morales (Chile), Erna Scheffler (Germany), and Lady Brenda Hale (United Kingdom).
} 
levels of the judiciary. Likewise, once a woman is selected to peak court, there may be pressure to maintain levels of diversity by replacing vacancies made by women with other women judges (Arrington 2018). The selection of the first woman, while insufficient for gender parity, is a necessary first step in the diversification process. What explains the timing of the first woman to a country's peak court?

In answering this question, we look to scholarship on the underrepresentation of women in the judiciary, as all-male courts reflect a radical form of underrepresentation. Many of the potential causes of the underrepresentation of women on peak courts involve deeply complicated sociocultural processes, including limited availability pools that follow from gendered appointments to lower courts (Anleu and Mack 2009; Epstein, Knight, and Martin 2003), elite networks that fail to identify qualified candidates (Hennette Vauchez 2015), informal qualifications that exclude women (Gill and Jensen 2020), and culturally structured role perceptions that make a prestigious judicial career simply easier for men to pursue (Feenan 2008; Kim 2009). Just as scholars interested in descriptive representation among members of parliament have focused on the rules for selecting candidates, judicial scholars have focused on appointment processes.

A central debate in the study of gender diversity in the judiciary centers on whether to centralize the appointment power in a small number of offices (or individuals) or to diffuse the appointment power across a relatively large number of offices (Bratton and Spill 2002; Gill 2012; Valdini and Shortell 2016; Williams and Thames 2008). The former design is thought to create opportunities for credit claiming and by so doing prevent coordination failures when multiple actors are responsible for selecting judges. In contrast, appointment processes that rely on a relatively large number of actors promote the construction of a wider pool of credible candidates and make it more likely that there will be at least one actor who is committed to diversification. A third perspective suggests that the concern with the number of actors in the appointments process may be misplaced. Diversity can be achieved with many actors or with few. What matters is a disruption to the process by which judges are typically appointed (Arana Araya, Hughes, and PérezLiñán 2020).

We study the effect of a change in the constitutional rules for appointing judges to peak courts on the rate at which the first woman justice is appointed to such a court. Drawing on existing literature, we develop institutional models of appointments in which a state's underlying pressure for institutional diversification influences the effects of rules. We then develop a robust empirical design that can be used by scholars working on related problems in other fields. Our study uses a Rosenbaum permutation approach for inference for matched pairs.

Typically, scholars focus on how institutional structures influence the proportion of women serving on a high court. Although these designs are potentially valid, as Hoekstra (2010) and Hoekstra, Kittilson, and Bond (2014) note, they rely on a number of assumptions that may not hold in practice. Focusing on the appointment of the first woman, while important in its own right, also improves the quality of our inferences. Given that peak courts vary in size across countries and years but are relatively small, comparing the proportion of women across courts invites a key conceptual challenge. For example, a five-judge bench with one woman has a greater proportion of women than a six-judge bench with one woman, but there is no compelling reason to think that one woman provides more diversity to the five-judge bench than the six-judge bench. There is also a practical consideration. Making accurate comparisons about the level or proportion of women on a court would require only making comparisons across courts with the same number of seats, a requirement that is simply not feasible given how diverse judicial institutions are across countries and years.

Our findings suggest that constitutional changes in appointment structures accelerate the selection of the first woman peak court justice. We find suggestive evidence that changes that either increase or decrease the number of actors tasked with selecting judges decreases the time it takes for an all-male court to diversify, and we find persuasive evidence that simply changing the process by which judges are appointed, even if changes do not affect the number of actors, causes a decrease in the time to the first female appointment. These findings are most consistent with the expectations of scholars who point to institutional disruptions as key drivers of diversification (e.g., Arana Araya, Hughes, and Pérez-Liñán 2020; Hughes 2007; Hughes and Tripp 2015).

The remainder of the paper is organized as follows. We first summarize existing institutional arguments about gender diversity on courts. Next, we develop a theoretical framework that formalizes existing arguments about the effects of selection institutions found in the literature. We then describe our research design, present our data, and summarize our results. Finally, we consider the implications of our study for future work on gender diversification in political contexts.

\section{THE ROLE OF APPOINTMENT RULES}

The institutional literature on gender diversity in the judiciary has largely focused on the number and nature of the actors responsible for judicial selections (Bratton and Spill 2002; Valdini and Shortell 2016; Williams and Thames 2008). A first perspective on the effects of appointment rules emphasizes the concentration of power to select judges on one or a small number of office holders, especially if those office holders are electorally accountable (Valdini and Shortell 2016). Some empirical studies have suggested specifically that executive appointment mechanisms promote greater diversity on courts (Bratton and Spill 2002; Williams and Thames 2008). The primary mechanism through which this works involves incentives for "credit claiming" (Valdini and Shortell 2016). Increasing the number of actors in an appointment process makes it more difficult for any one actor to claim credit for a 
successful process of diversifying the bench and also less likely that any one actor will take the blame for a failure (Arrington 2020). In short, increasing the number of actors creates a coordination problem over accountability for diversity outcomes.

A second perspective suggests precisely the opposite approach. In 2007, the Venice Commission issued a report advocating for appointment processes that weaken the control of the executive by making use of diverse appointments commissions (Venice Commission 2007). Scholars have questioned the effect of merit commissions on diversity (e.g., Arrington 2020; Goelzhauser 2016; 2018), but experts continue to look for alternatives to centralized models. For example, Kowal (2016, 21) writes, "To have any claim to legitimacy, a twenty-first-century method of judicial selection must be more effective in delivering a judiciary that reflects our diverse communities. Reformers should explore ways to bring a diverse array of stakeholders into the selection process." Gill's (2012) analysis is supportive, finding that the proportion of women on high courts is related to the number of actors playing a role in the process.

The argument for an increase in the number of actors responds to a different type of problem than coordination failures over credit claiming. Adding more actors promotes diversity of voice - for example, those from the different branches of the national government, the legal academy, the judiciary itself, and civil society. To the extent that traditional recruitment patterns favored traditional (i.e., male) judicial candidates, adding new actors to the selection process should expand candidate pools and make it more likely that women will be included.

While the more general literature on institutional effects on gender diversity in political bodies is robust and varied, ${ }^{3}$ a growing literature focuses on the role of fundamental disruptions to the selection process (e.g., Fallon, Swiss, and Viterna 2012; Hughes 2007). Hughes (2007) finds that extra-constitutional closures of legislatures for a significant amount of time are associated with increases in gender diversity once legislatures are reopened and new elections run. Scholars have also found that exiting civil conflict is sometimes associated with increased legislative representation of women (Fallon, Swiss, and Viterna 2012; Hughes 2009; Hughes and Tripp 2015; Tripp 2015). Applying the logic of institutional disruption to the context of Supreme Court and Constitutional Court appointments in Latin

\footnotetext{
${ }^{3}$ The literature on gender diversity in politics has certainly emphasized the role of electoral rules, from proportional representation generally to particular list designs (e.g., Stegmaier, Tosun, and Vlachová 2014; Valdini 2012; Yoon 2004). It has also held a vibrant debate over the use of gender quotas (e.g., Baldez 2006; Krook 2006; Tripp and Kang 2008). Judicial scholars have also addressed quotas or goals as potential drivers of diversity on courts (a summary is found in Hoekstra 2010). In her case for gender quotas for the Supreme Court of the United Kingdom, Malleson (2014) claims "The main argument in favor of quotas is that, unlike all other methods, they are guaranteed to work." Yet, Hoekstra (2010) reminds us that an early attempt to ensure gender diversity on the Supreme Court of Ecuador via a quota did not increase the proportion of female judges.
}

America, Arana Araya, Hughes, and Pérez-Liñán (2020) focus on events that result in the replacement of the majority of a court's seats, what the authors refer to as "reshuffles." They present evidence suggesting that reshuffles lead to an increase in the percentage of judges on a court who are women. Similarly, Kang et al. (Forthcoming) find that women are more likely to be selected when a new court is first formed, when all seats need to be filled simultaneously and there is enhanced visibility, and Dawuni and Kang (2015) argue that the combination of a strong women's movement combined with the end of armed conflict may explain the selection of women leaders to high courts in Burundi, Rwanda, and Sierra Leone.

These different perspectives share a concern with identifying features of society and politics that condition the effect of institutions. Hoekstra, Kittilson, and Bond (2014) suggest that the diversity of legislative bodies are the key to ensuring judicial diversity. Specifically, they argue that legislative gender quotas affect high court diversity by creating diverse legislatures, which help push for greater diversity in justice institutions. Hughes and Tripp (2015) note how the effect of the disruption of armed conflict on women's legislative representation depends on the international context. Specifically, the end of strife has a larger effect on the increased presence of women in the 1990s and early 2000s relative to earlier years due to the international pressure to improve the status of women associated with the 1995 UN Conference on Women in Beijing. In the US state supreme court context, Bratton and Spill (2002) find that executive appointment only promotes greater diversity when courts are all-male. The difference they observe between executive appointment schemes and appointment via elections is insignificant once at least a single woman is on the bench. What these studies suggest is that the underlying social pressure for diversifying political office shapes how institutions influence diversity.

Existing arguments are persuasive but important questions remain. Underlying social pressure for diversification should influence the ways that institutions influence appointment outcomes, but how? Should institutional form be most important when social pressure is weakest or strongest? The institutional disruption literature has focused our attention on changes to general political processes, but there is no account of how disrupting the particular rules for appointing judges might influence diversity. Moreover, disruptions may shape the diversification of all-male courts through a few mechanisms. In the next section, we develop models designed to capture the essential logic of the first two perspectives, which have focused on particular institutional rules. We then consider how an institutional disruption approach might inform that analysis.

\section{MODELING APPOINTMENTS FOR GENDER DIVERSITY}

Our goal in this section is to further develop existing arguments that link judicial selection institutions to 
diversity on the bench. We focus on the number of actors with control over selection. We will conceive of appointment rules for increasing gender diversity as influencing a kind of public goods provision problem, where diversifying a court is the good.

\section{The Appointment Process}

We assume that an appointment process can be described by an integer, $n \geq 1$, which represents the number of individuals empowered to appoint a judge to a court. Each individual chooses from the set $G=\{M, F\}$. A slate of appointed judges is characterized by a list $l=\left\{g_{1}, g_{2}, \ldots, g_{n}\right\}$ of judge genders $g_{i} \in G$ for appointers $1, \ldots, n$. We will say that an appointment process is considered a success if at least one member of $l$ is $F$. Finally, we will assume that there is pressure in society for the appointment of a woman, which we will denote $v \in(0,1)$, where values of $v$ closer to 1 indicate stronger pressure for a female appointment.

\section{A Model of Interdependent Choices}

We first consider a model that reflects the critical concern of scholars who promote centralized appointments processes-for example, executive appointments. We show in this section that even if all actors involved in the process can take equal credit for a successful process of diversification, coordination failures result as the number of actors increases. The familiar reason is that large groups encourage a kind of shirking over diversification. This problem is very clearly exacerbated when credit claiming is related to group size. As the literature suggests, when credit must be shared with others, diversification is even less likely as group size increases.

We model this process as an $n \geq 2$ player public goods provision game in which each player benefits identically from a successful search. ${ }^{4}$ Let the utility value of success be $v>0$, so that the value increases in underlying sociopolitical pressure for diversity. All selectors obtain $v$ if any one of them appoints a woman. We will relax this assumption, but it is useful to isolate the effect of credit claiming versus the reliance on others to provide a public good. We also assume that each appointer confronts a personal opportunity cost, $c \in(0,1)$, for selecting the female candidate. This cost might be very small, as when the female candidate under consideration is strongly preferred for reasons unrelated to gender. The cost might be relatively large when the opposite is true.

Consider the symmetric mixed strategy Nash equilibrium of this game, where each appointer appoints a female candidate with probability $p_{i}$. An equilibrium strategy profile in this game is a list of $n$ probability distributions over $G$ such that $p_{i}=p_{j}$ for all players $i$ and $j$. For this profile to be an equilibrium with all $p_{i} \in(0,1)$, we first require that there is sufficient social

\footnotetext{
${ }^{4}$ The simplest model we can identify to illustrate this point is a textbook public goods provision game. This model is elaborated by Osborne (2003) among others.
}

pressure for diversification (i.e., $v \geq c$ ). If there is not, then all appointers will set $p=0$.

Recognizing that the utility of appointing a woman is $v-c$ for each appointer, for equilibrium we require that this value is equal to the expected value for each appointer of choosing a male judge. This expected value is the utility of at least one woman being chosen by any of the other appointers (i.e., $v$ ) multiplied by the probability that at least one of them appoints a woman. Because the probability that no other appointer selects a woman is $(1-p)^{n-1}$, for this kind of equilibrium, we require that the following holds for each appointer: ${ }^{5}$

$$
\begin{gathered}
v-c=v\left(1-(1-p)^{n-1}\right), \text { which implies that } \\
\frac{c}{v}=(1-p)^{n-1} .
\end{gathered}
$$

Solving for $p$ gives the equilibrium probability with which each appointer selects a woman judge:

$$
p^{\star}=1-\left(\frac{c}{v}\right)^{\frac{1}{n-1}} .
$$

Because this equilibrium requires that the value of diversification $(v)$ exceeds the individual opportunity cost $(c)$, as the number of appointers $(n)$ increases, the probability with which each appointer selects a woman approaches 0 . Yet, by adding appointers, there are more individuals available to select a woman, so the key question is whether the additional appointer (who also uses $p^{\star}$ ) offsets the reduction in each appointer's probability of selecting a woman.

Equation 2 illustrates that in any equilibrium, the probability that any combination of $n-1$ members selects a woman is independent of the number of appointers. This probability merely reflects the ratio of opportunity costs to the value of diversification. In so far as any single member of the group's probabililty of seleting a woman goes down as group size increases while the probability that the remaining members of the group select a woman is independent of group size, the group as a whole is less likely to diversify the bench as the number of appointers increases.

Large groups are sufficient for coordination failure even if every member can claim credit equally. But what if individual credit claiming declines in group size? Suppose that the value of diversifying the bench to each member of the group is $\frac{v}{n}$, so that the value of the appointment to each individual declines as the group becomes larger. In this case, coordination failure is even more likely as group size increases because both (1) the probability that any group of $n-1$ members fails to select a woman increases in $n$ and (2) the probability that any individual selects a woman continues to decrease in $n .{ }^{6}$

\footnotetext{
${ }^{5}$ Because every appointer chooses the same $p$ in equilibrium, we suppress the index.

${ }^{6}$ Specifically, in this version of the model, the probability that no other actor chooses a woman is $\frac{c n}{v}$, the probability that any individual selects a woman is $1-\left(\frac{c n}{v}\right)^{\frac{1}{n-1}}$. Equilibrium in this case requires that $v>c n$.
} 


\section{FIGURE 1. Effect of an Appointer Increase, by Pressure}

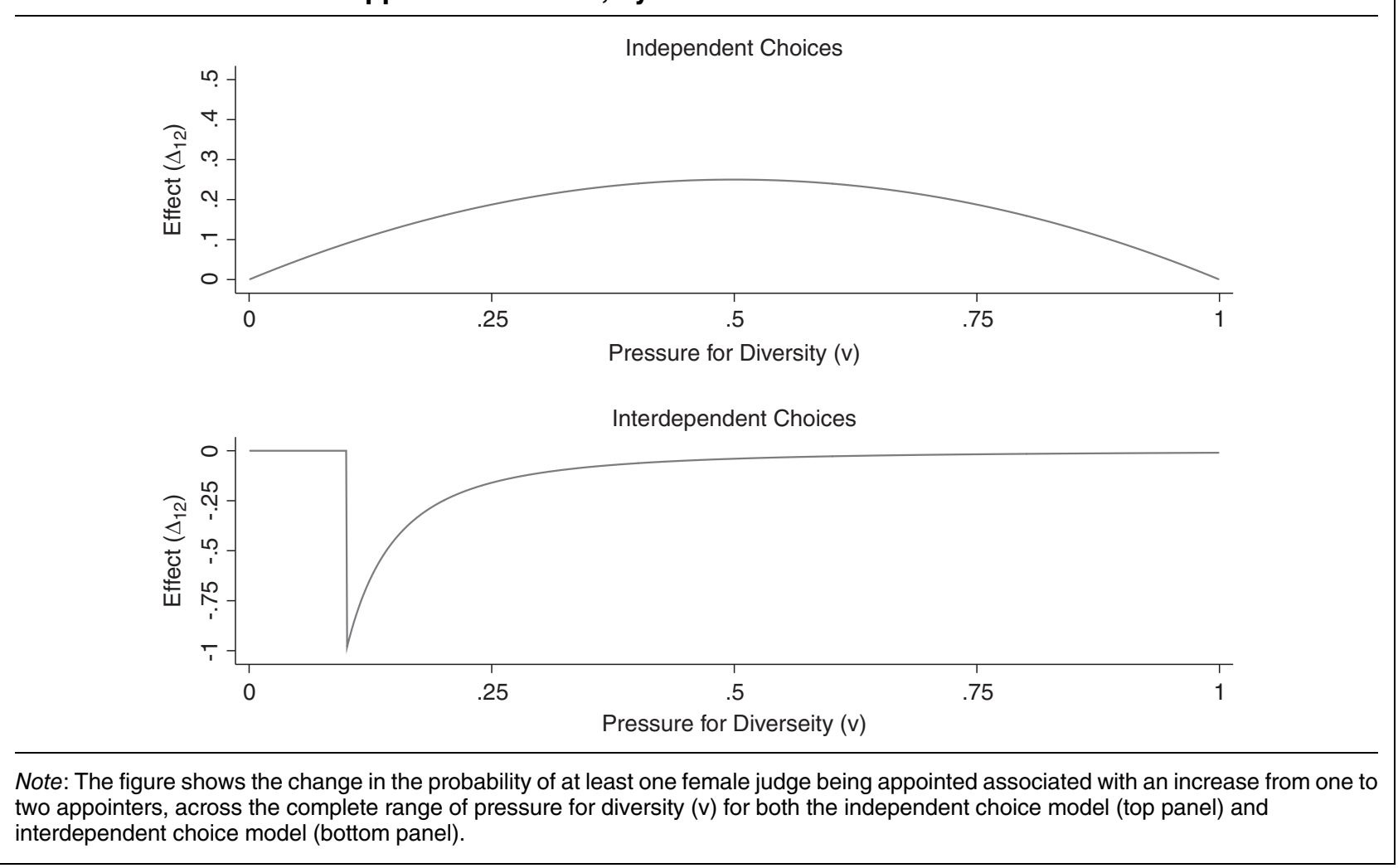

\section{A Model of Independent Choices}

The second perspective on appointments rules suggests that larger groups of appointers are preferable in order to ensure that diverse voices and candidates are heard and considered. This implies that choices are likely independent of each other. Each appointer brings something special to the process. To capture this logic, consider a probability model of choice. We will continue to assume that the choices of the appointers are still linked to underlying social pressure for diversity. Specifically, let the probability that appointer $i$ sets $g_{i}=F$ be represented by $v$, so that appointers are increasingly likely to choose a female judge as pressure for diversity increases. The number of female judges appointed via this process is a random variable with distribution $B(n, v)$, so the probability of $k$ women being selected in an appointment process is given by

$$
\left(\begin{array}{l}
n \\
k
\end{array}\right) v^{k}(1-v)^{n-k}
$$

Given our definition of success, we are interested in the probability of at least one woman being appointed in a search. This probability is

$$
1-\left(\begin{array}{c}
n \\
0
\end{array}\right) v^{0}(1-v)^{n}=1-(1-v)^{n}
$$

which very clearly increases in group size.

\section{The Conditional Effect of Institutions}

If appointments are conceived of as interdependent, then increasing group size decreases the likelihood of diversification because of coordination failures, and, if choice is conceived of as independent, then increasing group size has the opposite effect because adding additional appointers simply gives the group more chances to diversify. Yet both models demonstrate how appointment rules should interact with underlying pressure for diversity.

Figure 1 summarizes this result. Both panels plot the change in the probability that at least one female judge is appointed as the number of appointers is increased by one, given the underlying pressure for diversity $(v){ }^{7}$ The top (bottom) panel shows the case of independent (interdependent) choices. Both panels clearly indicate that the largest effects are at moderate levels of pressure for diversifcation. ${ }^{8}$

In both models, when the demand for diversification is strong, every appointer is likely to identify and select a qualified woman. In such contexts adding appointers

\footnotetext{
${ }^{7}$ Specifically, we plot $\operatorname{Pr}(k \geq 1 \mid n=2)-\operatorname{Pr}(k \geq 1 \mid n=1)$, where $k$ is the number of women appointed in a process and $n$ is the number of appointers.

${ }^{8}$ The discontinuity in the bottom panel reflects the difference in the probability of a successful search at relatively low pressure, where a single appointer would select a female judge but a pair of appointers would not.
} 
has a very small effect. For a similar reason, where demand for diversification is weak, adding an additional appointer will have a relatively low effect. In fact, in the case of interdependent choice, once $v$ falls below $c$ there simply is no chance of diversification. It is at moderate levels of pressure where institutional form should make a meaningful difference, making the coordination problem easier to avoid on the first account and meaningfully adding an additional voice to the process on the second. This analysis suggests the following two propositions:

Interdependent Choice: When choices are interdependent and the pressure for diversification is low, adding appointers to an appointment process has no effect on the probability of having at least one woman on a court. For sufficiently high levels of pressure, adding appointers (weakly) decreases the probability of a female appointment. Assuming that pressure is sufficient to increase diversity at all, the effect of adding appointers is strongest at moderate levels of demand, relative to either low or high demand.

Independent Choice: When choices are independent, the probability that a court has at least one woman judge increases in the number of appointers, but the effect is strongest at moderate values of demand for diversity, relative to low or high values.

\section{How Might Institutional Disruption Affect Diversification?}

An alternative explanation for why institutional change might accelerate the diversification of all-male courts focuses less on specific institutional arrangements and more on the opportunities that arise from institutional disruption and a change in the status quo (Valdini 2019). One natural force to consider is that changes in constitutional rules for appointing judges to peak courts create opportunities for domestic and international groups that promote gender equality to mobilize and pressure for diversification. Constitutional reform in the twentieth century was often carried out in the context of a mobilization for rights. Women's groups targeted both substantive rights provisions as well as efforts to make decision-making bodies of the state more inclusive (Alvarez 1990; Kenny 2013; Mackay 2014; Waylen 2007). It is possible that in this context, a change in the rules for judicial appointments would have created a space to link broader constitutional reforms with particular interests in the diversification of courts. Simply, a change in the appointments process could have resulted in an increase in the social pressure for diversification ( $v$ in our models). The consequence of a significant increase in $v$ is that courts will diversify independently of whether constitutional reform increased or decreased the number of actors in the appointments process.

A second possibility is that by changing the appointment process, constitutional reform disturbs traditional networks of judicial recruitment. The second perspective on the role of appointment institutions promotes multiactor processes for identifying candidates; however, it is possible that eliminating the number of actors in the process could encourage an actor who remains to consider a new process of recruitment. This mechanism also suggests that a change in the number of actors in an appointment process should promote diversification, but it is also possible that other changes to the process that do not affect the overall number of actors trigger this mechanism as well. ${ }^{9}$ These mechanisms suggest the following empirical implication.

Institutional Disruption: Any change in the appointments process should increase gender diversity. These changes include increases and decreases in the number appointers as well as changes in the process in which the number of appointers is not changed.

\section{RESEARCH DESIGN}

Testing for the effects of constitutional change on gender diversification presents two broad concerns regarding research design: the proper control of confounding and the valid and reliable measurement of the outcomes. Additionally, our solution to the first problem (using changes and the over-time nature of the data) makes the second concern more salient.

Differing adoption times for appointment systems greatly complicate attempts to control for confounding. Consider the United States, which adopted its system in 1789: any control variable measured after 1789 could potentially induce posttreatment bias with respect to the United States. Generalizing this intuition to a global sample, any control variable measured recently could induce posttreatment bias with respect to many countries. This possibility for posttreatment bias greatly complicates the measurement of confounding variables, which for some countries must be measured far in the past, and leads us to focus our analysis on the effect of changes in appointment systems. By focusing on changes in the appointment system, we can control a great deal of confounding by matching on the prior appointment system and on values of the outcome variable prior to the adoption of that system (Abadie, Diamond, and Hainmueller 2010). However, this approach puts considerable weight on our ability to measure the outcome variable accurately at each point and to match on values of that outcome variable. Focusing on the appointment of the first woman to a peak court, while important in its own right, thus has important methodological benefits.

Our approach also addresses a critical conceptual challenge. Imagine that a second woman is appointed to a five-judge court and a second woman is appointed to a six-judge court. Can we really say that either the level or the increase in gender diversity on the first

\footnotetext{
${ }^{9}$ In the Online Appendix, we discuss a third institutional disruption mechanism, which suggests that different countries attempt to solve distinct problems via institutional reform.
} 
court is more meaningful than the level or increase on the second, as would be indicated by a proportion measure? In our approach, all units have all-male courts prior to treatment, so the selection of a woman justice means the same thing for each country: the first woman selected to the high court. Making accurate comparisons about the selection of the second, third, fourth, and so on women to the peak court would require matching treatment and control units on both the number of seats on the court and the number of women previously selected and/or currently on the court, a matching requirement that is simply not feasible given the lack of uniformity in court size across countries, the finite number of countries that have experienced constitutional change to selection procedures, and the finite number of courts that have experienced various levels of gender diversity.

Given our focus on all-male courts that experienced a constitutional change and to resolve the empirical challenges outlined above, we adopt a Rosenbaum (2002) permutation approach, which allows for nonparametric inference in small samples. The approach has been used in political science to evaluate the effects of electoral rules on opposition repression (Glynn and Ichino 2015) as well as the effect of ballot order on candidate success (Ho and Imai 2008).

Our design involves the following steps. First, we identify states that had relevant changes in their constitutional articles that define the process for appointing judges to a peak court. We refer to these states as treatment states. Second, we exact match each treated state to potential control states based on institutional features, and then we use propensity score matching to identify one control country for each treated country based on a number of variables suggested in the literature. Third, to conduct our analysis, we calculate a signed-rank statistic for each sample. For each pair of states, we calculate the difference in the number of years from treatment until the first woman appointment in either state. We then rank these differences. We use the statistic as described in Rosenbaum (2002). In this approach, the test statistic is the sum of the ranks of the differences for all pairs for which the treated state experienced a woman appointed to the peak court first. Under this approach, a statistic of 0 would indicate that the control state experienced the appointment of a woman first (or at the same time) for every pair. Results that are farther from 0 are consistent with outcomes in which a larger number of treated states experienced the appointment of a woman first.

For causal inference, the key assumption in this design is that - conditional on matching - the probability of assignment to each treatment condition is equal. However, given the relatively small sample size we might be concerned that any observable difference is simply due to chance. To address this possibility, we adopt a randomization approach to inference. Under this approach, the reference distribution for the statistic we calculate is constructed from our sample by permuting treatment assignments. Under the sharp null hypothesis, the treatment effect is zero for all units. Consequently, by permuting each treatment assignment within all pairs and then calculating the signed-rank statistic for each permutation, we can construct the distribution of test statistics under the null hypothesis. In other words, we compare the signedrank statistic we observed in our sample to the the distribution of all signed-rank statistics calculated for every possible allocation of treatment.

\section{Measuring the Appointments Process}

Our research team, associated with the Varieties of Democracy Project (V-Dem), collected information on appointment and removal institutions for peak courts. Working in cooperation with the Comparative Constitutions Project (CCP; Elkins, Ginsburg, and Melton 2009; n.d.), we developed descriptions of the appointment and removal institutions for peak courts in all states (and many former colonies), from 1900 to the $2015 .{ }^{10}$ Constitutionally defined procedures largely, though not always, focus on two stages. Formally, the identification of candidates as well the development of particular proposals takes place via what we will refer to as the "nominations stage," where a legally empowered actor proposes a name for a seat (For a careful discussion of the aspects of the appointment process, see Gill 2012). We will refer to each institutional actor empowered to name a candidate for a position on the court as a "nominator." This is often a president, in which case it refers to a particular individual. It can be a chamber of a legislature or a commission, which are clearly groups of people. By nominators, we refer to both types of actors. The second stage, which we refer to as the "appointments stage," involves a legally empowered actor assigning a proposed name to a seat. We refer to these actors as "selectors," again allowing the term to describe individuals as well as institutionally identified groups. We refer to the sum of nominators and selectors involved in a particular process of appointing a judge simply as "actors." In practice, the nomination and appointment/ selection stages can be combined in a variety of ways. Figure 2 describes four distinct constitutional processes for appointing constitutional court judges.

The Peruvian process, depicted at the top of the figure, is clearly the most simple. The Constitution of Peru creates a process in which nomination and appointment are assigned to the one institutional actor, the Peruvian Republic's Congress. Because the nomination and appointment/selection stages are collapsed into one stage, Peru is coded as having no nominators and one selector. The process for selecting Federal Constitutional Court judges in Germany is marginally more complex, two institutional actors - the upper and lower chapters of the German parliament-are each empowered to select one half of the judges who sit on the Federal Constitutional Court. As in Peru, though, within each chamber, the nominating and selection

\footnotetext{
${ }_{10}$ This includes constitutional texts not included in CCP's publicly available data.
} 


\section{FIGURE 2. Constitutional Processes for Appointing Constitutional Court Judges in Serbia, Germany, Mexico, and Peru}
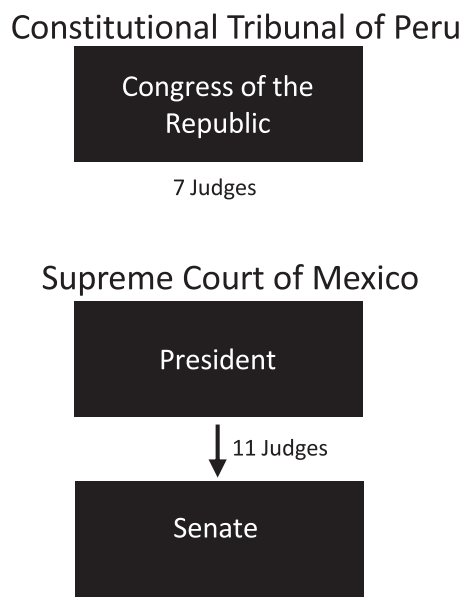

Federal Constitutional Court of Germany
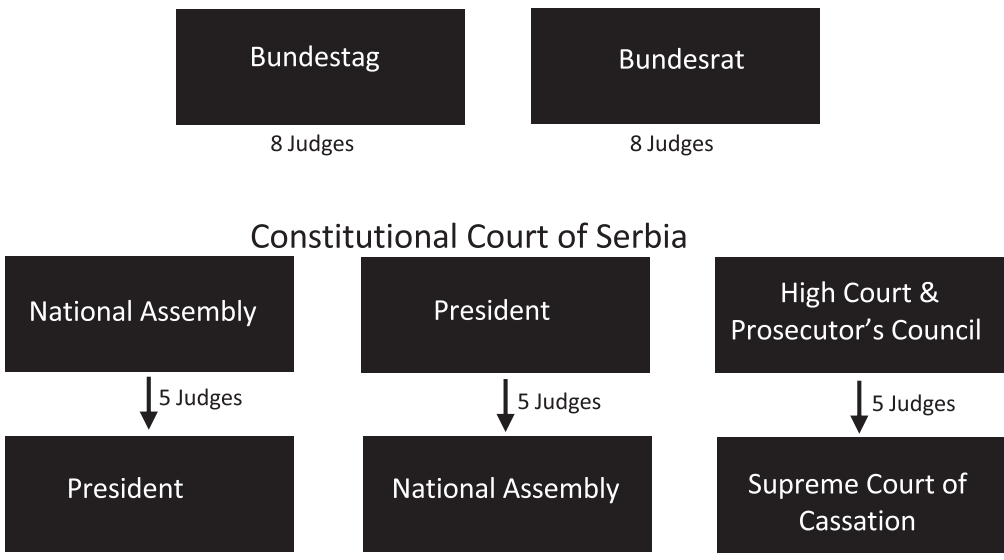

Note: The processes described in the figure reflect those in practice in 2011.

authorities are combined, so Germany is coded as having no distinct nominators but two selectors.

The processes of Peru and Germany contrast with those used to appoint members of the Mexican Supreme Court and the Constitutional Court of Serbia in that the nominations and appointments stages are assigned to distinct actors. In Mexico, the president nominates candidates but then the Senate appoints justices, so Mexico is coded as having one nominator and one selector. The Serbian process both separates the nominations and appointments stages and assign powers to multiple actors. Specifically, five judges are appointed via one of the following three processes: (1) the National Assembly nominates and the President appoints, (2) the President nominates and the National Assembly appoints, and (3) the High Court and Prosecutor's Council nominates and the Supreme Court of Cassation appoints. Serbia has four distinct institutional actors involved in appointments, but three actors involved in the nominations stage and three actors involved in the selection stage. The Serbian process, therefore, is coded as having three nominators and three selectors.

Because we coded each constitutional event over time, we are able to identify when and how the appointment processes for peak court judges changes. ${ }^{11}$ Our study focuses on changes made between 1970 and 2000 . Figure 3 illustrates what we understand to be a treatment state. The Constitution of Nicaragua was reformed in 1987 as a part of the institutionalization of the Sandinista regime. A part of the reform included a change in the appointment process for the Supreme Court. Like modern day Peru, Supreme Court justices were nominated and appointed by the National

\footnotetext{
${ }^{11}$ The exception is for a small set of countries for which CCP did not have an English-language constitution and our research team was unable to translate it. For constitutions not yet translated, we were only able to identify changes in the constitutions written in languages our coding team could read: English, Spanish, French, Portuguese, Dutch, Polish, Russian, Romanian, German, Finnish, and Norwegian.
} 
FIGURE 3. Nominations and Appointments Process for the Supreme Court Justices in Nicaragua

Treatment State: Nicaragua, 1987

$1962-1986$

National Assembly

Each judge

1987 -

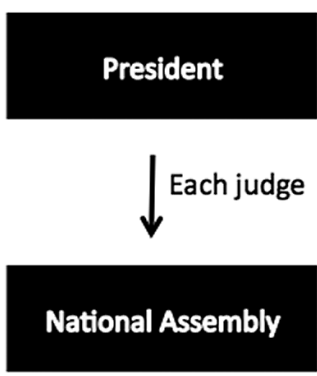

Note: The process involved a single actor, the National Assembly, from 1962 to 1982. In 1987 the Constitution was reformed and assigned the nomination power to the president, leaving the appointment power in the National Assembly.

Assembly from 1962 through 1986. The 1987 reform assigned nomination power to the president, leaving appointment/selection power in the National Assembly. This change reflects an increase from one actor in the appointment process to two actors and a change from no nominators and one selector to a process with one nominator and one selector. We thus can treat Nicaragua in 1987 as a treatment observation, where treatment is understood as an increase in the total number of actors in the process.

We focus on the total number of actors for two reasons. This represents the closest connection to the theoretical model. It also avoids a series of difficult choices over whether and if so how to weight the roles that nominators and selectors play in this process. In some settings, the nominators will be highly advantaged in a bargaining process but in others it will be the selectors. In so far as disadvantaged bargaining partners anticipate the reactions of the advantaged partners, it may be nominators propose to selectors exactly whom selectors want. Absent an account to guide us in identifying exactly the actors who matter in every process, we are conservative and simply count the total number of nominators and selectors in the process. That said, we will consider the robustness of our findings to alternative conceptualizations of the treatment.

\section{Treatments}

We conduct four tests, each of which investigates a different constitutional change, corresponding to a distinct prediction associated with our theoretical arguments. Our first analysis tests whether an increase in the number of actors accelerates diversification, as suggested by the interdependent choice model. For this analysis, we define treatment as a constitutional change in which the number of institutional actors tasked with nominating or selecting justices increases. In the second analysis, we test for the effect of an institutional change that results in a decrease in the number of nominators or selectors on the selection of the first woman justice, as suggested by the independent choice model. This analysis is the same as the analysis for the increase in actors above, except here we define treatment as a constitutional change that decreased the number of actors tasked with selection.

The third and fourth analyses test for the effects of institutional disruption on the selection of the first woman justice. For these analyses, we define treatment as, first, a change in the selection process that either increases or decreases the number of actors and, second, as any change to the selection institutions. Defining treatment as any change captures increases in the number of actors, decreases in the number of actors, and changes to the selection process that do not change the number of actors, including cases like Afghanistan in 1976 in which the process changed from the king appointing justices to the president appointing justices. Here the number of actors remains the same (one), but the process changed nonetheless. Defining treatment as any change also captures increases in the court size or term limits (both of which shape turnover), the addition or removal of advisory roles, ${ }^{12}$ or a change in the nature of selection such as a shift from appointment to election. ${ }^{13}$

\section{Matching}

For our first two analyses, we first exactly match treated units to control units that had the same pretreatment institutions (precisely: the same number of nominators and selectors) to the treated unit in the year of treatment using the CEM package in R (Iacus, King, and Porro 2009). ${ }^{14}$ Then, among those potential control countries that matched exactly on institutions and year,

\footnotetext{
${ }^{12}$ For example, in 1999 Senegal altered the process so that the Superior Council of the Court of Accounts advises the president.

${ }_{13}$ Costa Rica 1989, for example, transitioned from the legislative assembly appointing justices to the legislative assembly electing justices with a two-thirds majority

${ }_{14}$ As we show in the Online Appendix, our models of interdependent and independent choice suggest that the effects of a change in rules depend on the prior rules, and thus exact matching on the prior rules is consistent with these accounts.
} 
we use the Optmatch package (Hansen and Klopfer 2006) to propensity-score match on a variety of covariates suggested by the literature described in the next section. Because we are testing for the effects of institutional change on the selection of the first woman justice, we limit our analyses to countries with historically all-male courts.

For our third and fourth analyses, the theoretical argument does not suggest that the effects of institutional change are dependent on prior institutional forms. Rather than exact matching on the year and pre-change institutions, then, we exactly match units on the year and the type of constitutional event associated with the reform. For these analyses, a treated country that experienced a change in the selection process through a constitutional amendment is matched to another country that had a constitutional amendment in the same year, but the amendment did not affect the judicial selection process. By matching on constitutional event, we ensure that the institutional disruption within a pair is either specific to the judiciary or comes from a constitutional amendment more generally. After exactly matching on year and event type, we again use propensity-score matching to generate matched pairs.

\section{Matching Variables}

We include several potential confounding variables in the analysis. First and foremost, we include the percentage of women in the lower house of a country's legislature or parliament. ${ }^{15}$ We also seek to condition on the amount of time since universal suffrage was granted for each country (also from Paxton, Green, and Hughes 2008). We expect that the longer women have had access to political power through voting, the greater will be the pressure for increased access to institutional positions of power for women. Similarly, it is possible that pressure for constitutional reform is linked to the time since universal suffrage. To capture a broader set of features that are associated with social pressure to diversify and to reform constitutional processes, we also include a Women's Political Empowerment Index from the Varieties of Democracy project. This index was created through point estimates of a Bayesian factor analysis model of several variables: women's participation in civil society participation, percentage of female journalists, freedom of domestic movement for women, freedom of discussion for women, freedom from forced labor for women, property rights for women, access to justice for women, and power distributed by gender (Coppedge et al. 2016). All of these measures should be associated with an underlying social pressure for or preference for gender diversity on peak courts.

\footnotetext{
${ }^{15}$ Data are from the Inter-Parliamentary Union, but we used versions collected by (Paxton, Green, and Hughes 2008) for years 19702003 and (World Bank n.d.) for years 2003-2010. Missing data between two observed data points were filled in with liner interpolation. In addition, if there were no women in legislative office, preceding missing values were filled in, likewise, as zeros.
}

In addition to the Female Empowerment Index, we include several additional indices and measures from the Varieties of Democracy Project. The Egalitarian Democracy Index measures the extent to which the ideal of egalitarian democracy - that is, the extent to which there is an equal distribution of political power across social groups such as class, sex, religion, and ethnicity - is achieved in a given country year. Similarly, the Participatory Democracy Index measures the extent to which all citizens can be active in the political process.

We also include a series of variables from the Varieties of Democracy Project. Specifically, we use a measure of court packing, a measure of the extent to which women have access to justice, a measure for whether and the extent to which power is distributed by gender, a measure of women's civil society participation, a measure of the presence of female journalists, a measure of the freedom of domestic movement for women, a measure of the freedom of discussion for women, a measure of the extent to which women are free from forced labor, and a measure of the extent of property rights for women. Table 1 lists these variables and summary statistics for the full, unmatched dataset. ${ }^{16}$

\section{Matching Consequences}

Figure 4 helps evaluate the consequences of matching. It shows the standardized differences in means across treated and control countries for the unmatched data and for matched samples for the first analysis in which treatment is defined as an increase in actors. ${ }^{17}$ The open circles indicate standardized differences in means (treatment means minus control means divided by the control standard deviation) for the unmatched sample. The black points show the same information for the matched sampled data. As expected, exact matching on the number of nominators and appointers as well as the year produces perfect balance. Although there was good balance in the unmatched sample with respect to the number of appointers, treated states had far fewer nominators on average. Thus, the unmatched sample would not permit valid comparisons. Although balance is not perfect for the remaining variables, it is significantly improved for the most significant potential confounder, the percentage of women in the lower house of the legislature.

Matching ensures that we are making sensible comparisons in our analysis, comparisons that are interpretable in light of existing theoretical logics. Yet, there are costs of ensuring valid comparisons. Specifically, the costs lie in a reduced sample size. Table 2 provides a summary of the consequences of our matching approach. The first column of the table shows the set

\footnotetext{
${ }^{16}$ We used linear interpolation to fill in any missing values in years between observed data points. To see summary statistics of the full, global dataset compared with the sample of units included in the studies, see table A.4 in the Online Appendix.

${ }^{17}$ See Figures A.4 and A.5 in the Online Appendix for balance for other analyses.
} 
TABLE 1. Summary Data for the Matching Variables for the Full, Unmatched Dataset for the Years 1970-2010

\begin{tabular}{lcccc}
\hline Variable & Mean & SD & Min & Max \\
\hline Year & 1992 & 11.58 & 1970 & 2010 \\
Number of nominators & 0.55 & 0.98 & 0 & 9 \\
Number of selectors & 1.26 & 0.77 & 1 & 6 \\
Percentage of women in parliament & 10.56 & 9.15 & 0 & 56.30 \\
Years since universal suffrage & 42.11 & 21.8 & 0 & 117 \\
Court packing index & -0.03 & 1.1 & -4.21 & 2.26 \\
Freedom of discussion for women & 0.55 & 1.64 & -3.55 & 3.87 \\
Property rights for women & 0.85 & 1.33 & -3.74 & 3.00 \\
Participatory Democracy Index & 0.3 & 0.22 & 0.015 & 0.83 \\
Power distributed by gender & 0.05 & 1.1 & -2.98 & 4.20 \\
Access to justice for women & 0.52 & 1.51 & -3.84 & 3.55 \\
Freedom from forced labor for women & 0.85 & 1.08 & -3.94 & -4.52 \\
Freedom of domestic movement for women & 1.02 & 1.33 & 2.82 \\
Percentage of female journalists & 29.7 & 13.43 & -3.06 & 3.53 \\
Women's civil society participation & 0.77 & 1.15 & 0.02 & 3.24 \\
Egalitarian Democracy Index & 0.36 & 0.26 & 0.0005 & 0.99 \\
Equality of law and individual liberty & 0.6 & 0.3 & 0.92 \\
\hline
\end{tabular}

Note: The percentage of women in parliament variable comes from Paxton, Green, and Hughes (2008) and the World Bank (n.d.). The timing of universal suffrage variable is from Paxton, Green, and Hughes (2008). The variables from court packing index through equality before the law and individual liberty come from the Varieties of Democracy Project (Coppedge et al. 2016). For the V-Dem variables and the percentage of women in parliament, some missing values were interpolated, using the ipolate function in Stata.

\section{FIGURE 4. Standardized Difference of Means between Treated and Control Units for Both the Full Dataset and the Matched Dataset}

Number of Nominators
Number of Selectors
Yercent Women in Parliament
Court Packing Index

of state years in which there was an increase in either the nominators or appointers in a selection process for peak courts. The second column displays the set of control states for pairs for which there was a suitable control country and for which we have outcome data for both countries. The third column of the table shows the set of states that had a constitutional reduction in the number of nominators or appointers, as well as the matches for those states (fourth column). The key point here is that there are at most 15 pairs of states for either analysis.

The matching process also makes clear two features of this kind of analysis that are blurred in cross-national regression analyses. As Table 2 highlights, treated units 
TABLE 2. Consequences of Our Matching Approach

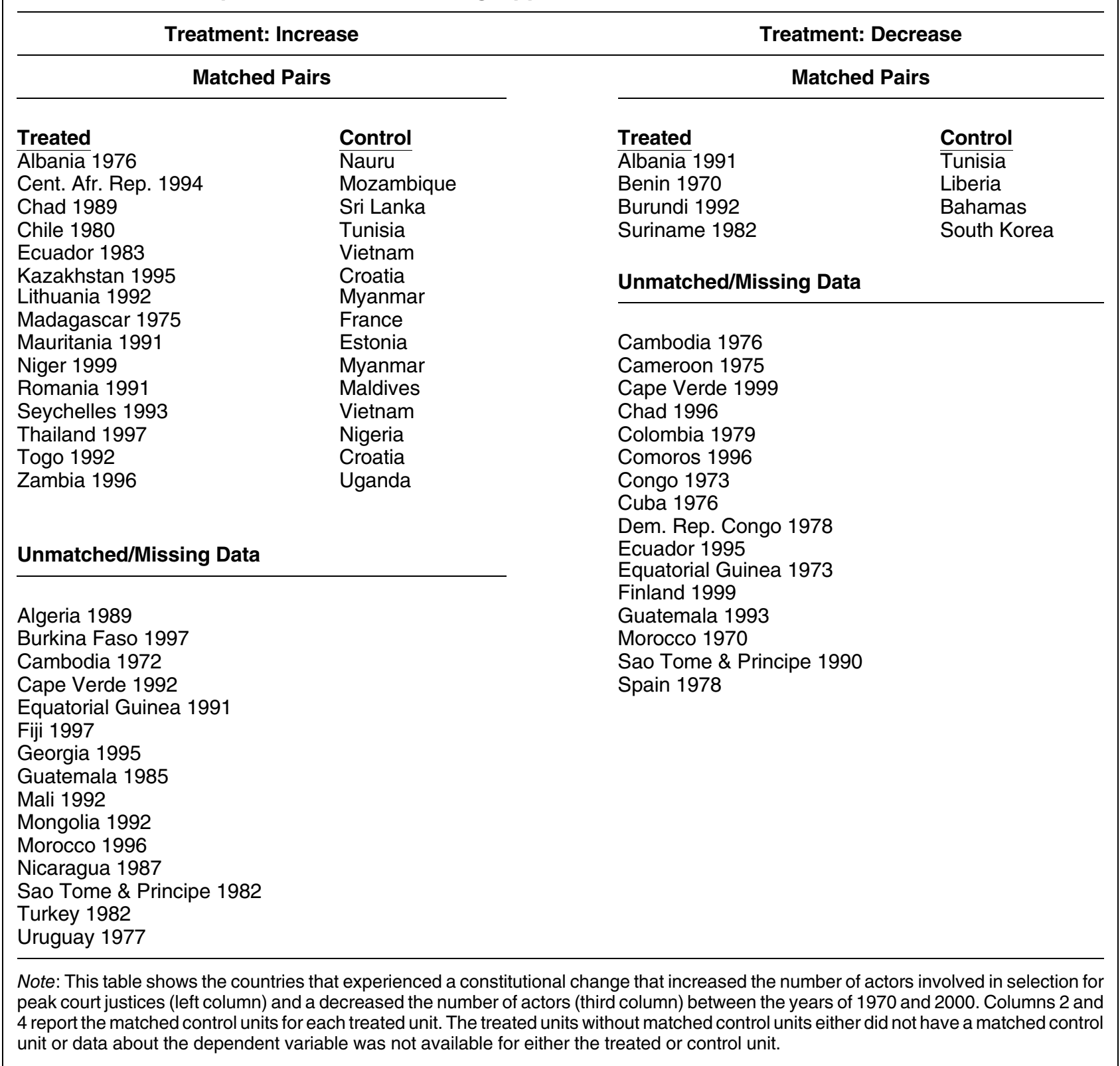

largely come from the developing world. In addition, our comparisons across institutional forms require us to compare states across regions so that, for example, Chile in 1980 is matched to Tunisia in 1980. Exactly matching on region is infeasible.

After matching we are left with a sample of pairs of states. Recall that the outcome of interest is the time in years from institutional change until the appointment of the first woman to the court of interest. We are interested in whether treatment decreases this time; however, the models of interdependent and independent choices suggest that effects will be most pronounced where social pressure to diversify is moderate. Following Hoekstra, Kittilson, and Bond (2014) we use the percentage of women in the lower chamber of a state's legislature to measure this pressure. Our threshold for "moderate pressure" is having more women in legislative office than the median percentage of women at the start of our sample in 1970 , which is $2.8 \%$ women in office.

\section{Analysis}

As outlined above, for each matched pair we calculate the signed-rank statistic based on the difference in time until the selection of the first woman justice between the treated and control units in each matched pair, generate a permutation distribution, and compare the observed signed-rank statistic with the distribution of all signed-rank statistics calculated for every possible 


\section{FIGURE 5. Increase in the Number of Actors}

Permutation Distribution, Increase in Actors

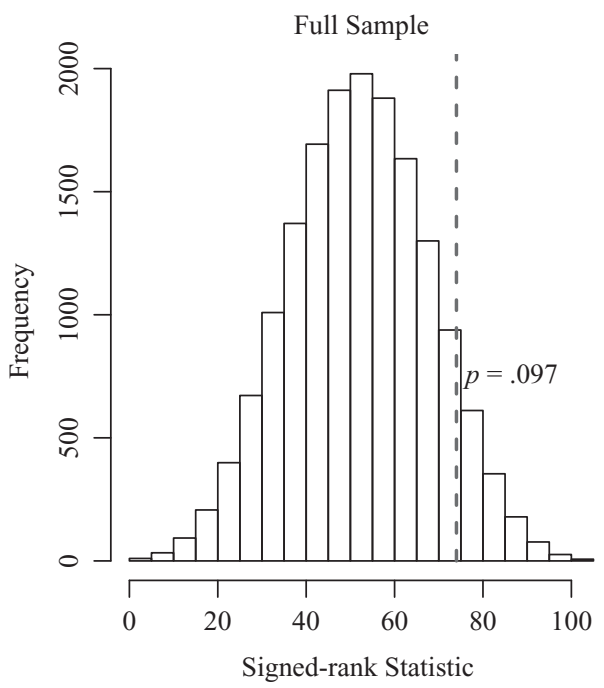

Permutation Distribution, Increase in Actors

Moderate Pressure Sample

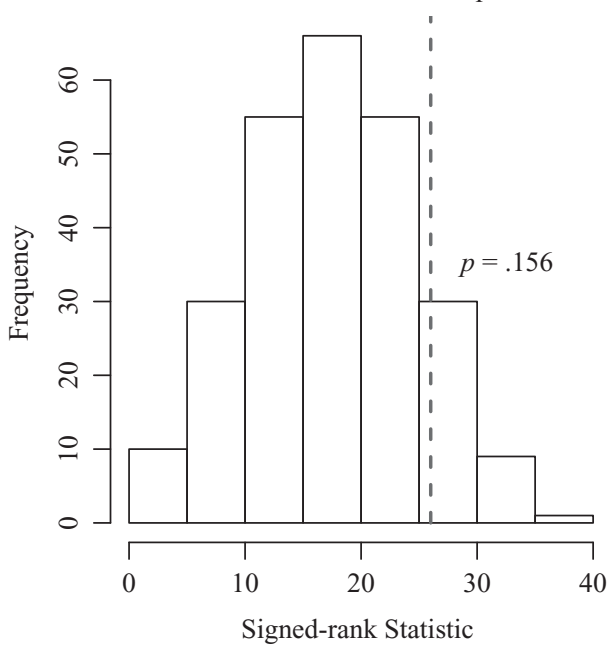

Note: The figure shows the permutation distributions for the signed-rank statistic associated with each sample. The plot on the left shows the analysis for the full sample of treated units (14 matched pairs), whereas the figure on the right shows the same analysis for states identified as having moderate degrees of pressure for diversification (eight matched pairs). The signed-rank statistic that we calculate is displayed as the red dashed line in the figure. One-tailed $p$-values are listed.

allocation of treatment. We can then calculate the probability of observing the outcomes we see under the null hypothesis in which treatment assignment is independent of the outcome (the selection of the first woman justice).

\section{The Effect of an Increase in the Number of Actors}

Figure 5 shows the results of our procedure where we define the treatment as an increase in the total number of actors in the appointments process. The histograms display the reference distribution for our test statistic, where the red, dashed line indicates the statistic calculated in the sample. The left panel shows the results for the full sample, ${ }^{18}$ and the right panel focuses on states where our measure of the percentage of women in the national legislature is consistent with moderate pressure for diversification. The treated countries in our sample select their first woman justice about five years, on average, faster than the control countries. The onetailed $p$-value is 0.097 for the full sample of states and 0.156 for the moderate pressure sample (where we theoretically should observe the largest effect).

\section{The Effect of a Decrease in the Number of Actors}

Figure 6 shows the results of a similar analysis but where we define treatment as a decrease in the number of actors. Here it is important to recognize that there are only four pairs of states in the analysis. All four

\footnotetext{
${ }^{18}$ The pair of Zambia and Uganda drop out of the analysis because both courts diversified in the same year.
}

treated units saw the selection of the first woman peak court justice before their matched control unit. On average, the treated countries selected the first woman peak court justice nine years before the control countries, and the one-sided $p$-value is 0.063 .

When treatment is defined as an increase in actors (that should open up recruitment networks) and when treatment is defined as a decrease in actors (which should help solve the coordination problem of selecting a woman), the treated countries in our samples select a woman-on average-sooner than the control countries. However, we cannot rule out the possibility that these patterns are due to chance, nor do these results suggest that either mechanism is the clear "solution" to facilitating the selection of women justices to all-male courts.

\section{Institutional Disruption}

In all, we have weakly positive results for both types of institutional change. What might account for these results? A plausible explanation in line with existing literature is that institutional disruption accelerates the selection of the first woman to an all-male court. Within this explanation, though, there are at least two distinct mechanisms. Institutional change focuses attention on judicial selection and creates space to link broader constitutional reforms with particular interests in diversification. Similarly, changes to the selection process may alter traditional recruitment patterns in ways that create opportunity for women candidates.

As we discuss above, we exactly match on the year of the constitutional change and the type of event that 
FIGURE 6. Decrease in the Number of Actors

Permutation Distribution, Decrease in Actors

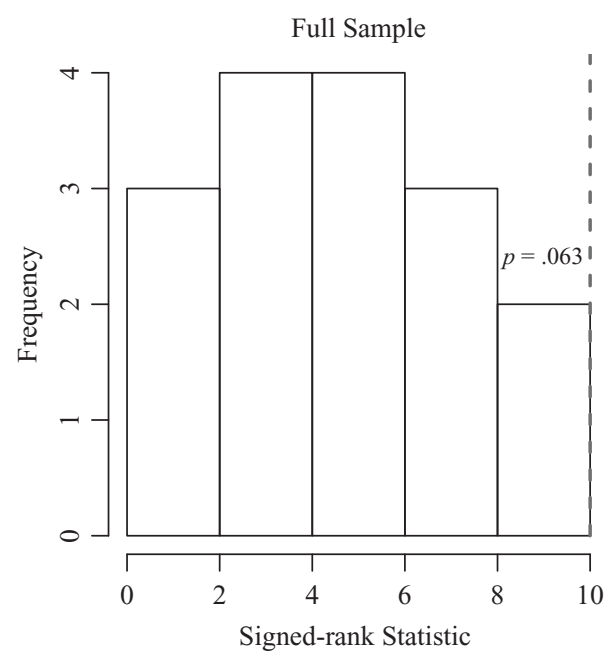

Permutation Distribution, Decrease in Actors

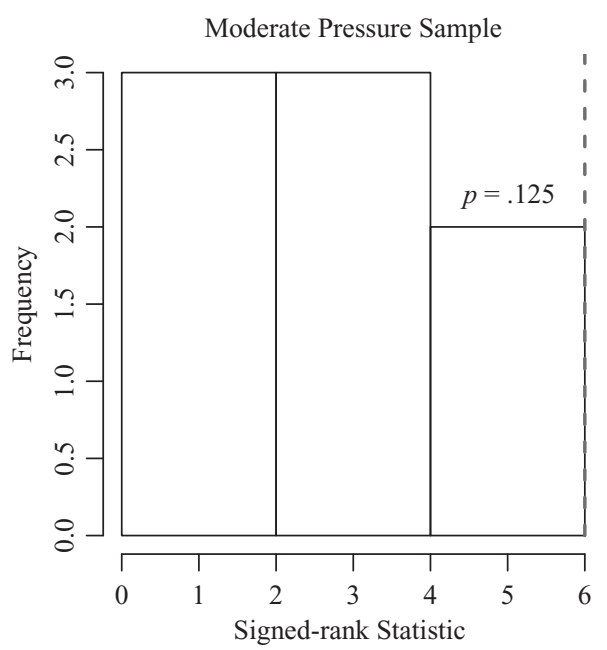

Note: The plot on the left shows the permutation distributions for the signed-rank statistic for the full sample (four matched pairs), whereas the figure on the right shows the same analysis for pairs with moderate pressure to diversify (three matched pairs). The signed-rank statistic is displayed as the dashed line in the figure. One-tailed $p$-values are listed.

resulted in the change. Exact matching on constitutional event type means that treated countries in which the appointments process changed as a result of a new constitution are matched to control countries that also experienced a new constitution and countries whose selection procedures changed as a result of an amendment are matched to control countries that also had a constitutional amendment. Matching in this way rules out the possibility that inferences regarding changes in the precise terms of judicial appointment are confounded by more general constitutional change. ${ }^{19}$

Figure 7 shows the results of the analysis in which treatment is defined as either an increase or a decrease in the number of actors. The results are fairly striking. Treated countries in our sample see the selection of the first woman judge, on average, over a decade faster than control countries. The signed-rank statistic for the full sample is very far from zero and statistically significant $(p=0.0017)$ and survives the Bonferroni correction for multiple comparisons. This analysis suggests that disruption is more important than the specific institutional form of a constitutional change, but this result is consistent with both mechanisms through which disruption decreases the time it takes to diversify an all-male peak court.

\footnotetext{
${ }^{19}$ Ideally, we would exact match on the pre-change number of nominators, selectors, year of change, and constitutional event, which is unfeasible. Exact matching on the pre-change number of nominators and selectors (and year) but not on the type of constitutional event that accompanied the change in the rules would be equivalent to combining the samples used to evaluate the increase and decrease in actors expectations. Combining those samples and recalculating the signed-rank statistic again suggests a positive effect $(p=0.02)$. Matching choices, here, shape the results.
}

As a second test of the effect of institutional disruption on diversification, we define treatment as any change in the selection process for peak court justices. Again, we exact match treated countries to control countries on year and type of constitutional event and then propensity-score match on the same variables used in the first two analyses. Because treatment is defined more broadly here, we end up with 33 matched pairs for which we have dependent variable data for both units. The sample size here makes the generation of the permutation distribution somewhat unwieldy, so we use a paired Wilcoxon test to determine whether treatment is associated with a the faster selection of the first woman justice. On average, treated countries select their first woman justice 3.7 years faster than control units; the one-sided $p$-value from the paired Wilcoxon test is 0.04 . This test suggests that any change to the selection process is associated with the earlier selection of the first female peak court justice. This result is consistent with the mechanism in which institutional change focuses attention on judicial selection and the mechanism that alters the actors involved in the process in ways that might create opportunities for previously overlooked candidates.

\section{CONCLUSION}

The first institutional arguments in law and courts scholarship connecting the process by which judges are selected to gender diversity on the bench placed analytical focus on the number of actors involved in the process. One approach identified a coordination problem over credit claiming that could be ameliorated by concentrating appointment authority in a small number 


\section{FIGURE 7. Any Change in Actors}

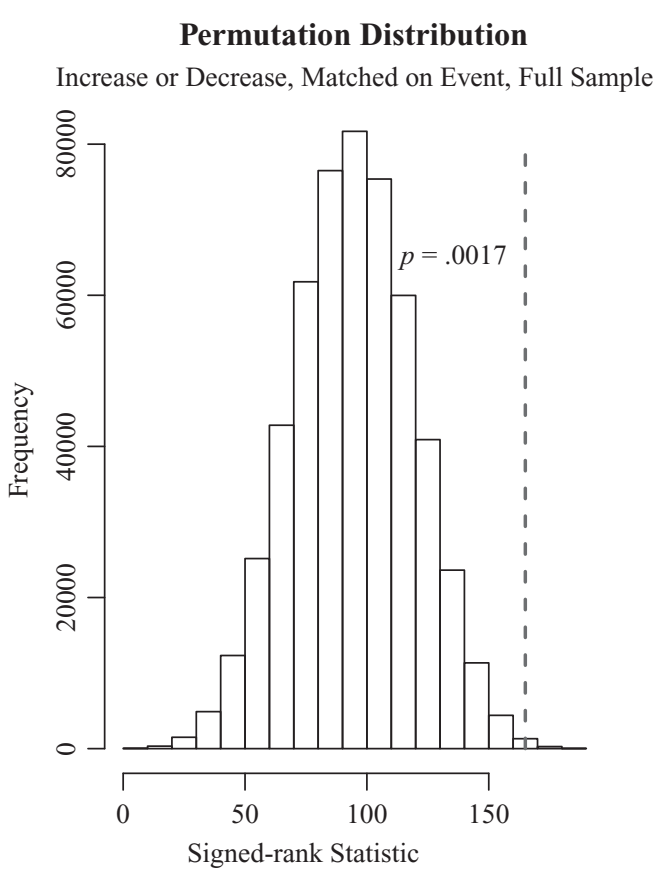

Note: This plot shows the permutation distribution and observed signed-rank statistic (the red line) for the 19 matched pairs for which we have data, with treatment defined as either an increase or a decrease in the number of actors.

of actors, ideally in a single person. A second approach identified the problem of limited recruitment networks, which could be best addressed by increasing the number of actors involved in an appointment process. Recently, judicial scholars have pointed toward the mechanism of institutional disruption, developed in scholarship on gender diversity in legislatures.

We report the results of a study designed to clarify these theoretical mechanisms, identify new empirical implications, and offer a robust empirical design for drawing causal inferences about the effect of institutional change on the appointment of the first woman to the peak court of a country. We find only suggestive evidence in favor of the dominant models developed in judicial politics. States that experienced either an increase in the number of actors or a decrease in the number of actors tasked with selecting judges did-on average-select the first female justice sooner than their control countries, but the statistical evidence is weak. It is also important to note that evidence consistent with the empirical implications of either one of these arguments is itself inconsistent with the other. Thus, at best our study finds both evidence in favor of and against both arguments that focus on the number of actors in the appointments process.

Our evidence is much more consistent with the institutional disruption account. We find that diversification is more likely when the constitutional rules for appointing judges to a peak court are changed. Further, we find evidence suggesting that diversification is caused by any change in the constitutional process for selecting judges, even if the changes do not increase or decrease the number of actors who make the selection. What matters is that the process changes.

These findings are consistent with those of Arana Araya, Hughes, and Pérez-Liñán (2020). They are suggestive of a mechanism in which constitutional reform creates an opportunity for pressure to be placed on political elites to identify new pools of qualified candidates. Although our empirical findings are restricted to the appointment of the first woman to a peak court, they are nevertheless important. Diversifying an all-male bench is a necessary first step in the process of a broad approach to diversity on the bench. Treatment cases in our sample are illustrative. As of the beginning of 2021 , women now compose $40 \%$ of the Supreme Court of Uruguay, $57 \%$ of the Constitutional Court of Zambia, and $44 \%$ of the constitutional court of Lithuania. These examples are consistent with evidence from the US states, which suggests that the first women judges to high courts are likely to increase pressure to replace female departures with women, thus creating a kind of minimal floor for diversity (Arrington 2018). Beyond the numbers, diversifying all-male benches is critical for symbolic reasons, and perhaps more importantly, for creating mentoring opportunities for women judges lower in the judiciary hierarchy (Dawuni 2016).

Our empirical approach makes it possible to draw more credible causal inferences. We do so by focusing on changes to constitutional processes, by making comparisons between matched states, and by adopting an approach to inference that is robust to our relatively small sample size and the pair-matching design. This 
approach does have consequences. The most important is that our sample is not representative of developed countries. Table A. 4 provides descriptive statistics for our matching variables as well as a few additional variables for states in our sample, states not in our sample, and the sample of Organisation for Economic Cooperation and Development (OECD) countries. The in-sample means for many of these variables are smaller than they are for the OECD set. For example, whereas the mean percentage of women in the legislature is roughly $8 \%$ in our sample, it is $15 \%$ in the OECD. Similarly, the average number of years since universal suffrage is just shy of 37 in our sample; it is over 58 years in the OECD. To be fair, the in-sample range covers the mean value of the OECD set, highlighting the considerable variation in our study; however, our sample is clearly not representative of developed states.

Still, a comparison of the in-sample and out-of-sample means suggests that our small sample of states is a fair representation of states in world (including OECD states). This suggests a useful point about the samples that we use to study politics. The fact of the matter is that relatively few states in the world are developed. Perhaps more importantly, most people $(82 \%)$ in the world live outside of the OECD. Related issues of gender in the law and gender on courts matters at least as much in the developing world as it matters in developed states (Dawuni 2016; Sieder and Barrera 2017).

Our approach also reflects the growing scholarship on comparative law and politics, which is ever more grounded in studies of developing countries. Hilbink and Ingram (2021,2) write, "Prior to the turn of the [twenty-first] century, political science and sociolegal literature on courts in developing countries was virtually nonexistent." This has changed dramatically in the last 20 years, where we have witnessed a massive expansion of comparative legal scholarship outside of Europe and North America. Hilbink and Ingram continue, claiming, "While spanning several disciplines, this boom in scholarship is especially noticeable in political science, where work on courts in developing countries now constitutes a major proportion of research in a subfield alternately labeled comparative judicial politics, comparative law and politics, comparative public law, or comparative law and courts." Our study connects naturally to this broad literature. It also offers a methodological approach that can be used in cross-national studies of law and courts, where scholars have long been interested in understanding the effect of particular institutions on judicial behavior (Helmke and Rosenbluth 2009).

It is nevertheless worth considering how our findings address diversification efforts in developed states. What might a change in the process by which judges for high courts are selected mean in such a state? If the institutional disruption mechanism for which we have evidence operates through the pressure that groups can place on elites charged with appointments, this pressure is likely to be channeled through the media. Table A.4 in the Online Appendix illustrates clearly that the public has greater access to media in developed states than in our sample; it also shows that the media in our study's sample is far less critical of governments than it is in developed states. This difference suggests that strong pressure for diversification through media channels would be easier to produce in the states underrepresented in our study, and for this reason, the effect of institutional disruption might be stronger.

It is also important to note that there is not an OECD country that has yet to appoint a woman to its peak court. However, there are other first appointments that might be considered. For example, at the beginning of 2021, considerable pressure was building on Joseph Biden to appoint the first Black woman to the Supreme Court of the United States (e.g., Carmon 2020). We might naturally ask how this pressure might look if the process for selecting justices were changed, say, by requiring the president to formally consult with a committee of legal experts. Our study suggests this kind of change would likely come with even stronger public mobilization in support of appointing the first Black woman to the Court. This pressure would likely be amplified considerably by the diverse and robust American media landscape.

We have focused on formal constitutional change and on the appointment of the first woman to a peak court, but the approach we adopt is adaptable to many settings outside of the judiciary. Our empirical approach can be used to study changes in subconstitutional rules and even in informal institutions. Similarly, it can be used to study other types of "first appointments" to courts or other politically relevant bodies. It can also be used to study other types of events, including the time between a change and appointment parity or some other threshold that has an important conceptual meaning.

\section{SUPPLEMENTARY MATERIALS}

To view supplementary material for this article, please visit http://dx.doi.org/10.1017/S0003055421000071.

\section{DATA AVAILABILITY STATEMENT}

All data and replication files are available at the American Political Science Review Dataverse: https://doi. org/10.7910/DVN/RHPSZD.

\section{ACKNOWLEDGMENTS}

We acknowledge and thank Erik Voeten, Sally Kenney, Gretchen Helmke, Lawrence Rothenberg, and Stefan Voigt for their comments on earlier versions of our paper. We also acknowledge and thank the Varieties of Democracy Project; the Comparative Constitutions Project; and discussants and audience members at the 2017 European Conference on Politics and Gender, the 2015 and 2016 annual meetings of the American Political Science Association, the 2016 Varieties of Democracy Conference, and the 2017 Pluricourts conference on Gender on the International Bench. 


\section{FUNDING STATEMENT}

This research project was supported by Riksbankens Jubileumsfond, Grant M13-0559:1, PI: Staffan I. Lindberg; by Knut and Alice Wallenberg Foundation to Wallenberg Academy Fellow Staffan I. Lindberg, Grant 2018.0144; by European Research Council, Consolidator Grant 724191, PI: Staffan I. Lindberg; as well as by internal grants from the Vice-Chancellors office, the Dean of the College of Social Sciences, and the Department of Political Science at University of Gothenburg.

\section{REFERENCES}

Abadie, Alberto, Alexis Diamond, and Jens Hainmueller. 2010. "Synthetic Control Methods for Comparative Case Studies: Estimating the Effect of California's Tobacco Control Program." Journal of the American Statistical Association 105 (490): 493-505.

Alvarez, Sonia E. 1990. Engendering Democracy in Brazil: Women's Movements in Transition Politics. Princeton, NJ: Princeton University Press.

Anleu, Sharyn Roach, and Kathy Mack. 2009. "Gender, Judging and Job Satisfaction.” Feminist Legal Studies 17 (1): 79-99.

Arana Araya, Ignacio, Melanie M. Hughes, and Aníbal Pérez-Liñán. 2020. "Judicial Reshuffles and Women Justices in Latin America." American Journal of Political Science. https://

onlinelibrary.wiley.com/doi/epdf/10.1111/ajps.12543.

Arrington, Nancy. 2020. "Judicial Merit Selection: Beliefs about Fairness and the Undermining of Gender Diversity on the Bench." Political Research Quarterly. https://journals.sagepub.com/doi/ 10.1177/1065912920971712.

Arrington, Nancy B. 2018. "Gender and Judicial Replacement: The Case of US State Supreme Courts." Journal of Law and Courts 6 (1): 127-54.

Baldez, Lisa. 2006. "The Pros and Cons of Gender Quota Laws: What Happens When You Kick Men Out and Let Women In?" Politics \& Gender 2 (1): 102-09.

Boyd, Christina L., Lee Epstein, and Andrew D. Martin. 2010. "Untangling the Causal Effects of Sex on Judging." American Journal of Political Science 54 (2): 389-411.

Bratton, K. A., and Rorie L. Spill. 2002. "Existing Diversity and Judicial Selection: The Role of the Appointment Method in Establishing Gender Diversity in State Supreme Courts." Social Science Quarterly 83 (2): 504-18.

Carmon, Irin. 2020. "What Will It Take to Get a Black Woman on the Supreme Court? The Fate of Biden's Campaign Promise Lies with Georgia." New York Magazine, December 22. https://nymag.com/ intelligencer/2020/12/what-will-it-take-to-get-a-black-woman-onthe-supreme-court.html.

Coppedge, Michael, John Gerring, Carl Henrik Knutsen, Staffan I. Lindberg, Jan Teorell, David Altman, Michael Bernhard, et al. 2016. V-Dem Dataset v6 [computer file]. Varieties of Democracy (V-Dem) Project, V-Dem Institute, University of Gothenburg [producer]. https://doi.org/10.23696/vdemcy16.

Dawuni, Josephine. 2016. Ghana: The Paradox of Judicial Stagnation. Chap. 9 in Gender and the Judiciary in Africa: From Obscurity to Parity? eds. Josephine Dawuni and Gretchen Bauer. New York: Routledge.

Dawuni, Josephine, and Alice Kang. 2015. "Her Ladyship Chief Justice: The Rise of Female Leaders in the Judiciary in Africa." Africa Today 62 (2): 44-69.

Elkins, Zachary, Tom Ginsburg, and James Melton. 2009. The Endurance of National Constitutions. Cambridge: Cambridge University Press.

Elkins, Zachary, Tom Ginsburg, and James Melton. N.d. "Comparative Constitutions Project: Informing Constitutional Design.” https://comparativeconstitutionsproject.org/. Accessed February 26, 2021.

Epstein, Lee, Jack Knight, and Andrew D. Martin. 2003. "The Norm of Prior Judicial Experience and Its Consequences for Career Diversity on the U.S. Supreme Court." California Law Review 91: 903-65.
Fallon, Kathleen M., Liam Swiss, and Jocelyn Viterna. 2012. "Resolving the Democracy Paradox: Democratization and Women's Legislative Representation in Developing Nations, 1975 to 2009." American Sociological Review 77 (3): 380-408.

Farhang, Sean, and Gregory Wawro. 2004. "Institutional Dynamics on the U.S Court of Appeals: Minority Representation under Panel Decision Making." The Journal of Law, Economics, and Organization 20 (2): 299-330.

Feenan, Dermot. 2008. "Women Judges: Gendering Judging, Justifying Diversity." Journal of Law and Society 35 (4): 490-519.

Gill, Rebecca D. 2012. "A Framework for Comparative Judicial Selection Research with an Application to Gender Diversity on High Courts." Working Paper. https://ssrn.com/abstract=1982705.

Gill, Rebecca D., and Christian Jensen. 2020. "Where are the Women? Legal Traditions and Descriptive Representation on the European Court of Justice." Politics, Groups, and Identities 8 (1): 122-42.

Glynn, Adam N., and Maya Sen. 2015. "Identifying Judicial Empathy: Does Having Daughters Cause Judges to Rule for Women's Issues?" American Journal of Political Science 59 (1): $37-54$

Glynn, Adam N., and Nahomi Ichino. 2015. "Using Qualitative Information to Improve Causal Inference." American Journal of Political Science 59 (4): 1055-71.

Goelzhauser, Greg. 2016. Choosing State Supreme Court Justices: Merit Selection and the Consequences of Institutional Reform. Philadelphia, PA: Temple University Press.

Goelzhauser, Greg. 2018. "Does Merit Selection Work?: Evidence from Commission and Gubernatorial Choices." Journal of Law and Courts 1 (6): 155-87.

Hansen, Ben B., and Stephanie Olsen Klopfer. 2006. "Optimal Full Matching and Related Designs via Network Flows." Journal of Computational and Graphical Statistics 15 (3): 609-27.

Helmke, Gretchen, and Frances Rosenbluth. 2009. "Regimes and the Rule of Law: Judicial Independence in Comparative Perspective." Annual Review of Political Science 12: 345-66.

Hennette Vauchez, Stéphanie. 2015. "More Women - But Which Women? The Rule and the Politics of Gender Balance at the European Court of Human Rights." European Journal of International Law 26 (1): 195-221.

Hilbink, Lisa, and Matthew C. Ingram. 2021. "Courts and Rule of Law in Developing Countries." In Oxford Research Encyclopedia of Politics. Oxford: Oxford University Press. https:// doi.org/10.1093/acrefore/9780190228637.013.110.

Ho, Daniel E., and Kosuke Imai. 2008. "Estimating Causal Effects of Ballot Order from a Randomized Natural Experiment: The California Alphabet Lottery, 1978-2002.” Public Opinion Quarterly 72 (2): 216-40.

Hoekstra, Valerie. 2010. "Increasing the Gender Diversity of High Courts: A Comparative View." Politics and Gender 6 (3): 474-84.

Hoekstra, Valerie, Miki Caul Kittilson, and Elizabeth Andrews Bond. 2014. "Gender, High Courts, and Ideas about Representation in Western Europe." In Representation: The Case of Women, eds. Maria C. Escobar-Lemmon and Michelle M. Taylor-Robinson, 103-17. New York: Oxford University Press.

Hughes, Melanie M. 2007. "Windows of Political Opportunity: Institutional Instability and Gender Inequality in the World's National Legislatures." International Journal of Sociology 37 (4): 26-51.

Hughes, Melanie M. 2009. “Armed Conflict, International Linkages, and Women's Parliamentary Representation in Developing Nations." Social Problems 56 (1): 174-204.

Hughes, Melanie M., and Aili Mari Tripp. 2015. "Civil War and Trajectories of Change in Women's Political Representation in Africa, 1985-2010.” Social forces 93 (4): 1513-40.

Iacus, Stefano, Gary King, and Giuseppe Porro. 2009. "cem: Software for Coarsened Exact Matching." Journal of Statistical Software 30 (1): $1-27$.

Kang, Alice J., Maria Escobar-Lemmon, Valerie Hoekstra, and Miki Kittilson. Forthcoming. "Breaking the Judicial Glass Ceiling: The Appointment of Women to High Courts Worldwide." The Journal of Politics. https://doi.org/10.1086/710017.

Kang, Alice J., Miki Caul Kittilson, Valerie Hoekstra, and Maria C. Escobar-Lemmon. 2020. "Diverse and Inclusive High Courts: A 
Global and Intersectional Perspective." Politics, Groups, and Identities 8 (4): 812-21.

Kenney, Sally J. 2019. "Towards a Less Essentialist, More Intersectional, and Institutional Approach to Gender and Judging." Connecticut Journal of International Law 34 (3): 400-19.

Kenney, Sally Jane. 2013. Gender and Justice: Why Women in the Judiciary Really Matter. New York: Routledge.

Kenny, Meryl. 2013. Gender and Political Recruitment: Theorizing Institutional Change. New York: Palgrave Macmillan.

Kim, Haesook. 2009. "The Avalanche Perspective: Women Jurists in Korea 1952-2008." Feminst Legal Studies 17: 61-77.

Kowal, John E. 2016. Judicial Selection for the 21st Century. New York: Brennan Center for Justice at New York University School of Law.

Krook, Mona Lena. 2006. "Gender Quotas, Norms, and Politics." Politics \& Gender 2 (1):110-18.

Mackay, Fiona. 2014. "Nested Newness, Institutional Innovation, and the Gendered Limits of Change." Politics \& Gender 10 (4): 549-71.

Malleson, Kate. 2003. "Justifying Gender Equality on the Bench: Why Difference Won't Do.” Feminist Legal Studies 11 (1): 1-24.

Malleson, Kate. 2014. "The Case for Gender Quotas for Appointments to the Supreme Court." UK Supreme Court [Blog], May 14. http://ukscblog.com/case-gender-quotas-appointmentssupreme-court/.

O'Connor, Sandra Day, and Kim K. Azzarelli. 2011. "Sustainable Development, Rule of Law, and the Impact of Women Judges." Cornell International Law Journal 44 (1): 3-9.

Osborne, Martin J. 2003. An Introduction to Game Theory. Oxford: Oxford University Press.

Paxton, Pamela, Jennifer Green, and Melanie M. Hughes. 2008. "Women in Parliament, 1945-2003: Cross-National Dataset." Inter-University Consortium for Political and Social Research [distributor], 2008-12-22. https://doi.org/10.3886/ICPSR24340.v1.

Rosenbaum, Paul R. 2002. Observational Studies. New York: Springer.

Sieder, Rachel, and Anna Barrera. 2017. "Women and Legal Pluralism: Lessons from Indigenous Governance Systems in the Andes." Journal of Latin American Studies 49 (3): 633-58.
Stegmaier, Mary, Jale Tosun, and Klára Vlachová. 2014. “Women’s Parliamentary Representation in the Czech Republic: Does Preference Voting Matter?" East European Politics and Societies 28 (1): 187-204.

Tripp, Aili Mari. 2015. Women and Power in Post-conflict Africa. Cambridge: Cambridge University Press.

Tripp, Aili Mari, and Alice Kang. 2008. "The Global Impact of Quotas: On the Fast Track to Increased Female Legislative Representation." Comparative Political Studies 41 (3): 338-61.

Turquet, Laura, Papa Seck, Ginette Azcona, Roshni Menon, Caitlin Boyce, Nicole Pierron, and Emma Harbour. 2011. Progress of the World's Women 2011-2012: In Pursuit of Justice. New York: United Nations Entity for Gender Equality and the Empowerment of Women.

Valdini, Melody Ellis. 2012. “A Deterrent to Diversity: The Conditional Effect of Electoral Rules on the Nomination of Women Candidates." Electoral Studies 31 (4): 740-49.

Valdini, Melody E. 2019. The Inclusion Calculation: Why Men Appropriate Women's Representation. Oxford: Oxford University Press.

Valdini, Melody E., and Christopher Shortell. 2016. "Women's Representation in the Highest Courts: A Comparative Analysis of the Appointment of Female Justices." Political Research Quarterly 69 (4): 865-76.

Venice Commission. 2007. Judicial Appointments (Report adopted by the Venice Commission at its 70th Plenary Session, March 16-17, Venice). The Venice Commission of the Council of Europe CDL-AD(2007)028-e. https://www.venice.coe.int/webforms/ documents/CDL-AD(2007)028.aspx.

Waylen, Georgina. 2007. Engendering Transitions: Women's Mobilization, Institutions and Gender Outcomes. Oxford: Oxford University Press.

Williams, Margaret S., and Frank C. Thames. 2008. "Women's Representation on High Courts in Advanced Industrialized Countries." Politics and Gender 4 (3): 451-71.

World Bank. n.d. "Proportion of Seats Held by Women in National Parliaments from the Inter-Parliamentary Union.” http:// data.worldbank.org/indicator/SG.GEN.PARL.ZS.

Yoon, Mi Yung. 2004. "Explaining Women's Legislative Representation in Sub-Saharan Africa." Legislative Studies Quarterly 29 (3): 447-68. 